\title{
A Case Study of the Adaptive Learning Platform in a Taiwanese Elementary School: Precision Education from Teachers' Perspectives
}

\author{
Tze Chang Liu' ${ }^{1}$
}

Received: 6 September 2021 / Accepted: 5 December 2021 / Published online: 6 January 2022

(c) The Author(s), under exclusive licence to Springer Science+Business Media, LLC, part of Springer Nature 2022

\begin{abstract}
This is a case study on precision education (PE) in a school using the Taiwan adaptive learning platform (TALP), established by the Ministry of Education of Taiwan. TALP can be viewed as a form of PE because it can identify students' learning deficits, offer various learning materials, and provide feedback. There are limited studies on PE. The ways in which TALP enhances teaching and learning is meaningful for educational technologies, and to help improve TALP and applications of PE. Three fifth-grade classes in a Taiwanese elementary school were selected to participate in this study, comprising a total of 76 students and two teachers. Pre/post tests and regular tests were conducted. The quantitative data were analyzed with nonparametric statistics by using the Kruskal-Wallis Test and the Median Test, which did not show significant differences. However, based on the qualitative data, teachers confirmed PE could help them identify students' learning deficits. Further, this study suggests that TALP and PE may enhance students' learning to identify students' learning challenges and offer feedback. Future research should focus on a longitudinal methodology and additional PE application studies; furthermore, research should also collect students' observations and interviews.
\end{abstract}

Keywords Elementary education · Media in education · Pedagogical issues · Improving classroom teaching - Data science applications in education · Adaptive learning

Technology is increasingly applied in education to enhance educators' teaching and students' learning experiences. Its application has been accelerated as a result of the COVID-19 (coronavirus) pandemic. The pandemic caused many schools to close;

Tze Chang Liu

tcliu0215@gmail.com

1 Institute of Professional Development for Educators, National Chung Hsing University, No. 145

Xingda Rd., South Dist, Taichung City 402, Taiwan 
teachers used digital technology to teach and connect with their students, while policymakers increasingly observed that unequal digital opportunities excluded some young people from education and social networks (Williamson et al., 2020). The pandemic also provides opportunities for online learning experiments (Zimmerman, 2020), and initiates global educational technology changes: platformization, datafication, privatization, and commercialization (Kerssens \& van Dijck, 2021; Selwyn, 2020; UNESCO, 2020; Williamson \& Hogan, 2020). Currently, there are several famous online teaching platforms, such as ALEKS, Knewton, Smart Sparrow, and Whatfix, among others (Das, 2018); each of them has distinct features and effects on teaching methods. Meanwhile, education is influenced by datafication, which not only shapes teaching and learning but also increases transparency, accountability, and participation, while posing challenges related to privacy, control, and inequality (Jarke \& Breiter, 2019; Williamson et al., 2020). Therefore, if the government can provide free learning platforms, this might offer more easy access and reduce inequality concerns. In 2018, the Ministry of Education of Taiwan (MET) supported the establishment of an online teaching platform called the Taiwan adaptive learning platform (TALP). MET also launched "the technology assisted self-regulated learning (SRL) project" (TASRLP) in 2020 to integrate digital technology, especially TALP, to support SRL in middle and elementary schools. MET provides funding to provision digital devices, such as laptops and tablet computers. The Taiwan government has also improved the digital environment in recent years so that schools can access the Internet easily. There were over 300 schools participating in TASRLP in 2020; it encourages in-class group cooperative learning by incorporating the use of digital technology to eventually achieve SRL. Even with low technological infrastructure and teachers who are willing but underprepared, a blended learning environment can positively change students' classroom learning engagements and encourage teachers (Kundu et al., 2021). TALP brings together teachers with expertise in different fields (subjects) to systematically develop course materials on the platform according to the national curriculum's standard syllabus. It uses artificial intelligence (AI) to make the whole system more interactive and support learning activities. An important aspect for consideration by TALP is AI-supported Education (AIED), which mainly focuses on knowledge representation, reasoning, and learning (Barnes et al., 2017; Self, 2016). Meanwhile, "the implementation of innovative learning tools" and "the approaches to apply these tools in real educational practices" are two challenges for AIED in computer science (Barnes et al., 2017). This case study tries to respond to these two challenges.

A characteristic of TALP is the knowledge structure it applies to individual fields, which are designed and constructed on the platform in a systematic manner according to the syllabus. TALP provides free knowledge texts, videos, quizzes, and interactive learning, making it easier for teachers to prepare lessons and for learners to learn independently. Simultaneously, a diagnosis system and knowledge star map for each unit, cross-unit, and cross-grade are provided, helping teachers and students understand their learning paths. Such an individual diagnosis system provides immediate feedback, helps teachers to grasp students' learning status, and helps students to reflect on their learning situation. TALP tends to offer an adaptive learning platform for students. This can support precision education (PE) because it 
can identify at-risk students in the early learning stage and provide information for teachers to offer interventions to assist learning. PE can provide early intervention to improve learning engagement and strategy (Yang, 2019). If teachers can promptly identify students who are at-risk learners, they may assist students to overcome learning challenges in their later learning process. Therefore, PE shows great potential to benefit both teachers and students. PE can intervene in students' learning at an early stage, before they are left behind in learning or encounter challenges which may lead them to give up on learning. However, there are limited studies on PE. This case study can help fill this gap. It illustrates the ways in which PE works in the real world and how it can be improved. Moreover, critical perspectives on AI and PE in education are also included.

Meanwhile, science, technology, engineering and mathematics (STEM) education is important but faces various challenges. This study can also help address some of these issues. Teachers believe that STEM education can positively impact students' learning process and outcomes (Margot \& Kettler, 2019; Park et al., 2016), and teachers have responded that they feel rewarded when they utilize STEM education to effect student and community changes (Goodpaster, et al. 2012; Hsu et al., 2011; Margot \& Kettler, 2019; Wang et al., 2011). STEM education can influence national competition capacity because STEM human resources can affect economic development. However, STEM education is being challenged, as students may learn insufficiently or leave due to difficulties in the learning process. This is because STEM pedagogy needs a fundamental transformation from teacher-led to studentcentered instruction (Lesseig et al., 2016; Margot \& Kettler, 2019; Park et al., 2017). To enable a transformation of this nature would involve changing pedagogy and curriculum design. Thus, teachers need to learn how to become facilitators of knowledge and how to support students learning STEM, taking academic risks such as the transformation to student-centered and student-led instruction (Margot \& Kettler, 2019). Teachers can learn and practice this through professional development before implementing it in classrooms (Margot \& Kettler, 2019).

Further, teachers self-report that they do not have enough instructional resources, which is an obstacle in offering students STEM learning opportunities (Margot \& Kettler, 2019; Park et al., 2017), including PE. This is especially urgent when a teacher has to manage a class of 20 or more students with diverse social and economic backgrounds. Teachers are worried about how to meet the diverse needs of different learners in STEM pedagogy, especially for students with disabilities and various cognitive abilities (Herro \& Quigley, 2017; Margot \& Kettler, 2019; Park et al., 2017). This leads to another challenge: how to effectively identify each student's learning difficulties and outcomes? Previous studies show that over $40 \%$ of teachers responded that they lacked assessments for STEM programs (Margot \& Kettler, 2019; Nadelson \& Seifert, 2013) and did not have enough formative assessments (insufficient standardized classroom assessments) to identify aspects of student learning (Asghar et al., 2012; Dare et al., 2014; Margot \& Kettler, 2019). PE may provide teachers with the information needed to assess STEM education. Therefore, this case study may also contribute to STEM education. A literature review on digital game-based learning suggested the need for further research on how different learning dynamics influence students' mathematical achievements (Hussein et al., 
2021). A well designed educational-based digital games can foster students' creativity and focus on learning (Behnamnia, Kamsin, Ismail, \& Hayati, 2020).

This study focuses on how TALP can support PE and enhance students' learning outcomes. The main standpoint was from teachers' perspectives on TALP and PE influences on students' academic development. Based on the challenges of STEM education and the adoption of TALP in some schools in Taiwan, this case study attempts to answer the following research questions:

(1) How does TALP assist teachers to conduct PE?

(2) How does TALP influence students' learning outcomes in math?

(3) Base on this case study, what can be improved to support PE?

\section{Background: Taiwan Adaptive Learning Platform and Case Setting}

\subsection{TALP Content}

TALP is a practical platform for PE that identifies, predicts, diagnoses, and assists learning (treatment). TALP's curriculum of Chinese, English, math, and science has been constructed for elementary to middle school students. TALP uses Information and communication technology (ICT) and AI to assist teaching and learning to conduct an adaptive learning platform that provides personalized learning for each student. TALP can identify students' learning deficits, create assessments, and offer various learning resources; its ultimate aim is to support students' self-regulated learning to fulfill their goal of becoming life-long learners. Figure 1 shows the main elements of TALP.

A characteristic of TALP is its knowledge structure for individual fields, which are designed and constructed on the platform in a systematic manner according to the official Taiwanese syllabus. TALP provides free knowledge texts, videos, quizzes, and interactive learning, making it easier for teachers to prepare lessons or for learners to learn independently. AIED is mainly focused on knowledge representation, reasoning, and learning (Barnes et al., 2017; Self, 2016), and TALP can use AI to support knowledge learning.

TALP includes six main sections. First, the learning 2.0 section provides resources for teachers to design their curriculum and by which students can conduct online learning and tests. The knowledge structure section provides a learning curriculum structure map that systematically shows the logical learning path of certain subjects. The knowledge structure is set by subject experts (both professors and experienced teachers) and offers the respective learning paths. Teachers and students can learn step by step according to the knowledge structure and learning paths. An intelligent diagnosis can analyze if the students learn in each node on their learning path (representing each small learning content). The intelligent diagnosis section can inform the teachers and students about the aspects that students did not understand and trace their past learning conditions. The TALP can provide information to help students fill their learning gap based on the intelligent diagnosis. This is one of the functions that may be used to conduct 


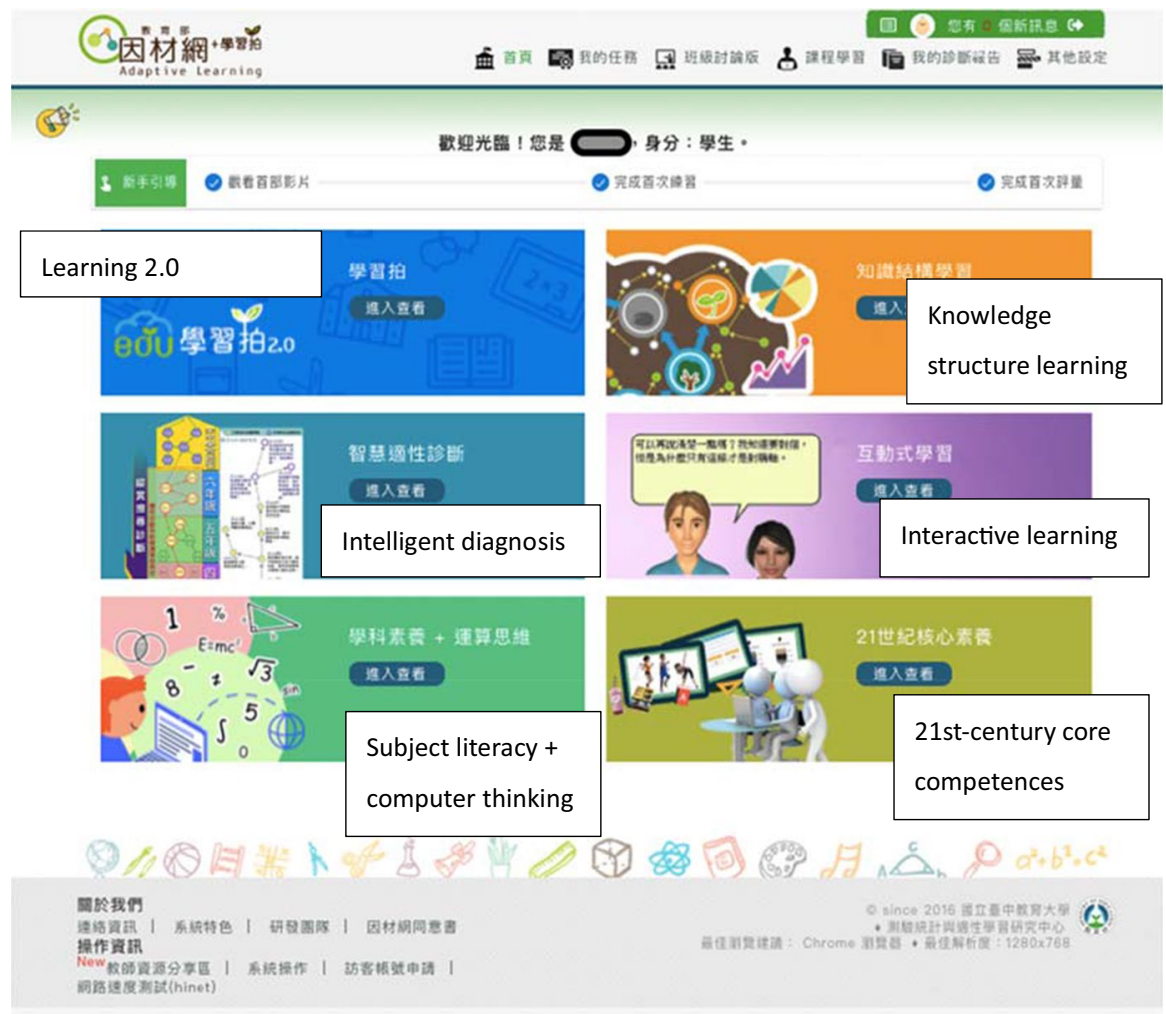

Fig. 1 TALP's main components (2019 version). Resource: https://school.cy.edu.tw/uploads/1582258824 792Xj5JNdEY.pdf

PE. The interactive learning section provides digital personal tutors that interact with students to help them learn. The subject literacy and computational thinking section provides additional learning resources to help students acquire knowledge and digital capacities, such as coding skills or computational thinking. The twenty-first-century core competencies section includes collaborative problemsolving and global competence emphasized by the Program for International Student Assessment (PISA). It offers some curricula for teachers to use in their classes.

TALP can also analyze individual students' learning paths. For example, if two students have problems learning the same topic, the reasons for this may vary. Figure 2 shows that both student $\mathrm{A}$ and student B got knowledge node "5-n12 " wrong. However, after conducting the TALP analysis, student A can trace how she/he did not understand " $2-n-06$ " or had misconceptions. Therefore, the teacher needs to either instruct student A on how to fill the learning gap or use TALP to provide learning materials for remediation. Meanwhile, student B also made a mistake on "5-n-12." The analysis reveals that "5-n-02," "5-n-03," and "5-n-01" are problems that student B needs to learn again to solve their initial 

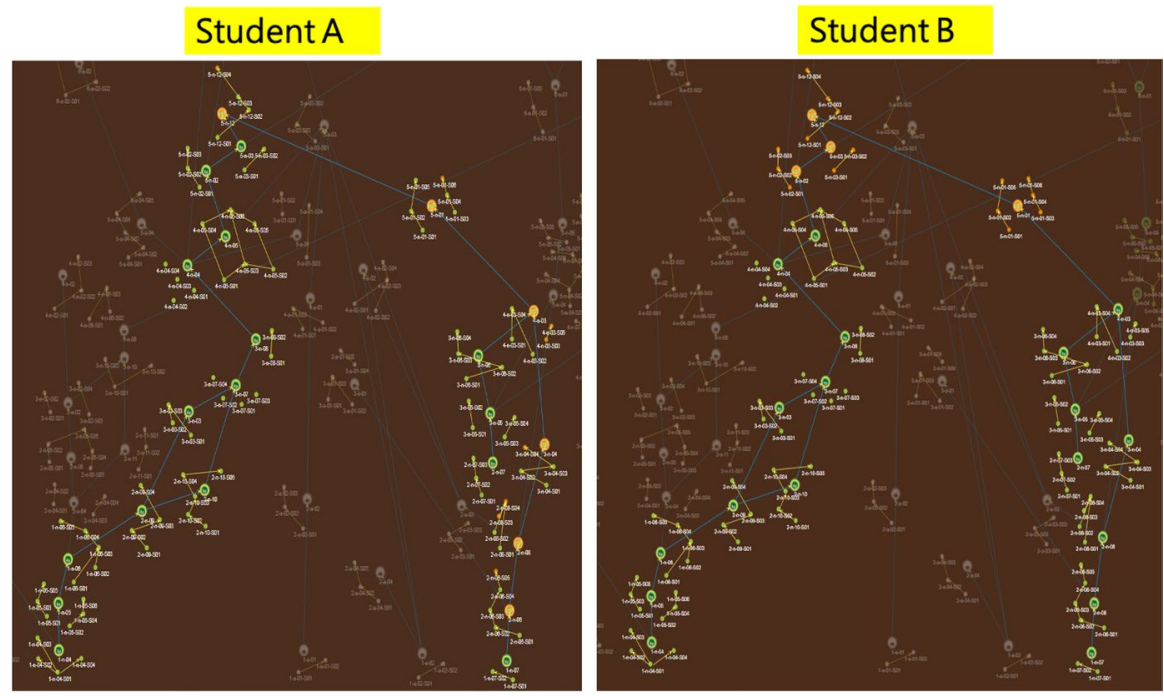

Fig. 2 Example of identifying personal learning paths; Resource: https://srl.ntue.edu.tw/download/㸴習 資源/數位學習工作坊(一)_1100929.pdf

misconceptions. Therefore, the teacher or TALP can offer different kinds of teaching topics and learning materials to student B compared to student A.

\subsection{Classroom Teachers and Contextual Elements}

This school participates in TASRLP and is located in mid-Taiwan in an urban area. Three elementary fifth-grade classes were chosen for this study. Class B used TAPL in the first semester, while classes $\mathrm{A}$ and $\mathrm{C}$ started to use it in the second semester, with implementation in class $\mathrm{C}$ two months earlier than class $\mathrm{A}$. According to teachers, most students in class $\mathrm{C}$ had lower academic performance and more family problems compared to students in the other two classes.

Two experienced schoolteachers, Max and Alan (pseudonyms), participated in this research. Classroom teachers have a core role in making curriculum decisions and affecting students' learning (Box et al., 2015). Teachers can orchestrate learning opportunities based on their choice of classroom-based interventions (Fishman \& Davis, 2006). Evidence confirms that teachers affect students' learning more than class size or socioeconomic background (Wiliam \& Leahy, 2006). Max and Alan used TALP (as well as some other online or digital resources) so that students could watch clips, practice tests, and analyze learning situations, in addition to regular lectures. They used TALP mainly to conduct PE and understand students' preparation and situation so that they could offer more adaptive learning supports. Four tests (exams) were designed by different schoolteachers as learning assessments. The first two tests were taken in the first semester while the third and fourth tests were taken in the second semester of the 2019-2020 academic year (which runs from August to 
July). These tests included midterm and final exams each semester. They were not standardized tests that designed by school teachers to understand how students were progressing in learning.

\section{Literature Reviews}

\subsection{Precision Education and Technology Critiques}

PE enhances personal learning and has been created based on previous digital technology development. AI includes problem-solving, representation and reasoning of knowledge, machine learning, and intelligent agents design and development (Barnes et al., 2017; Russell \& Norvig, 2016). For example, an AI-driven decision support system helps doctors make better decisions when performing diagnoses, predictions, or treatments by inputting patients' data and information into an AI system for analysis (Braun et al., 2020). Prediction models that underlie "early warning systems" should be improved; thus, the introduction of digital learning support to those students who were expected to perform poorly can improve their achievements (Bernacki et al., 2020). Likewise, PE also effectively enables the identification, prediction, and treatment of students' learning difficulties.

ICT development can certainly support PE. With the growing use of innovative digital education, collecting students' digital footprints can enrich new pedagogies (Fischer et al., 2020). By using teaching and learning experiences, PE aims to identify at-risk students as early as possible to offer timely intervention (Lu et al., 2018). Teachers can also use PE to understand students' learning situations, including the extent of their learning from previous courses and elements that they did not fully understand previously. Teachers play the most important role in the implementation of STEM programs (Margot \& Kettler, 2019; McMullin \& Reeve, 2014), and can, therefore, identify students' learning deficits and provide additional instruction to overcome students' learning gaps. Students can also understand and identify their learning situations to discover the specific part of their learning that is not fully understood. Based on identifying each student's difficulties in learning, teachers can offer interventions or students can self-regulate to improve their learning outcomes.

The COVID-19 breakout has pushed schools to use digital tools and online systems for teaching activities. However, using an online learning platform may also encounter some challenges and critiques. The networked society includes not only technology, but new economy, hierarchies, and changing values (Castells, 2011). Commercial companies or other actors (government, organizations, or think tanks) may influence learning platforms that shape education systems (Chang, 2019; Ideland, 2021; Williamson et al., 2019).

TALP provides PE to assist teachers in conducting innovative and personalized teaching. If teachers start to use innovative teaching methods or technology, students' learning may be enhanced, and thus could improve the learning process and outcomes of STEM education. Students may develop adaptive reasoning strategies if they view the classroom as task goals structured to develop conceptual understanding rather than memorizing (Young, 1997), which would ideally lead to 
enhanced student understanding of content knowledge and procedures (Sherwin, 2020). Therefore, teachers should support students with more in-depth instruction. Planning and implementation should be continuously offered alongside pedagogical tools for teachers to improve students' learning outcomes (Lesseig et al., 2016; Margot \& Kettler, 2019). TALP may offer innovative tools to teach students knowledge concepts and procedures.

\subsection{STEM Education}

There are six principles for K-12 STEM education: (1) math and science content, (2) student-centered teaching model, (3) lessons set in an engaging and motivating context, (4) involvement of engineering design or redesign challenges, (5) learning from making mistakes, and (6) emphasizing teamwork (Margot \& Kettler, 2019; Moore et al., 2014). These principles provide knowledge on how to conduct STEM education. Students may need substantial practice related to being involved in group work and hands-on activities to successfully learn STEM (El-Deghaidy et al., 2017; Herro \& Quigley, 2017; Margot \& Kettler, 2019). Hands-on and application activities are basic elements of STEM education that allow teachers to evaluate and understand the ways in which these elements can motivate their students (Bruce-Davis et al., 2014; Dare et al., 2014; Goodpaster et al., 2012; Huang \& Lin, 2014; Margot \& Kettler, 2019; van Haneghan et al., 2015).

Secondary teachers feel that engineering-based hands-on activities are especially helpful when students are learning math concepts (Asghar et al., 2012; Margot \& Kettler, 2019). However, teachers with math anxiety often adopt traditional delivery methods because of their comfort levels in such approaches (Finlayson, 2014). Some elementary school teachers with math anxiety are concerned that this may limit their students' performance in class (Ramirez et al., 2018). Thus, teachers must understand and adopt innovative teaching methods, which differ from traditional methods such as direct instruction. Moreover, programs focusing on knowledge, ability, motivation, and feelings of belonging may lead to increased interest and continuous STEM education (van den Hurk et al., 2019). Therefore, students can be motivated and may continue with STEM education if teachers use various forms of pedagogy to encourage students either inside or outside of the classroom.

This case study focused on math education, as one part of STEM. Math is an important subject in school that may influence future learning, but many students feel that learning math is difficult (Gafoor \& Kurukkan, 2015). Students may experience tension, anxiety, or fear of math-related events (Beilock \& Willingham, 2014). This math anxiety can restrict students' learning processes and outcomes. Therefore, schools and teachers need to find ways to reduce math anxiety and motivate students' learning. Technology can be important for improving mathematics proficiency (Shafique \& Irwin-Robinson, 2015). Innovative pedagogy and digital and other tools can be used to assist math learning.

In Taiwan, one of the primary concerns that teachers have raised is the lack of time for STEM education (Bagiati \& Evangelou, 2015; Goodpaster et al., 2012; Hsu et al., 2011; Margot \& Kettler, 2019; Park et al., 2016). Therefore, it is important to 
develop effective and efficient teaching in STEM. Some interventions may improve STEM pedagogy, such as value perception (Gaspard et al., 2015), adoption of ICT (Kara and Yeşilyurt, 2008), or increased hands-on experiences (Prokop et al., 2007).

Many ICT platforms supporting education or AIED show the potential utility of integrating technology to enhance education (Berendt et al., 2020; Martin et al., 2020; van Alten et al., 2020). However, previous studies on PE are limited, as it is a relatively new idea. The early diagnosis of students' learning conditions may offer a great advantage for teachers to assist students at an early stage. STEM education, on the other hand, is important but also challenging for many students. Studies show the potential of using ICT to support STEM education learning. Therefore, this study will further examine if TALP can truly enhance students' math learning. Some recommendations can be provided to improve STEM education.

\subsection{Self-Regulated Learning}

The significance of SRL is that a student shows conscious and active learning behaviors that involve metacognition, intrinsic motivation, and strategic action. Autonomous learning helps students to construct meaningful learning by themselves (Lin, 2018; Perry, 2002; Zimmerman, 1990). Zimmerman (1990), following Bandura's (1986) social cognition theory, first proposed the SRL cycle model. There are three stages in the cycle. The first is the "foresight stage," which focuses on motivations such as self-efficacy, goal orientation, result expectations, and task interest/value. The model emphasizes the use of task analysis to determine goal setting and planning for this stage. The second is the "performance/control stage," which emphasizes performance or control of the task execution process and examines the gradual achievement of goals. The third is the "self-reflection stage," which mainly emphasizes the process of self-assessment and interpretation (Efklides, 2011; Lin, 2018; Pintrich, 2000; Zimmerman, 1988, 2008; Zimmerman \& Kitsantas, 1997). SRLrelated theories include the self-determination theory (Deci \& Ryan, 2008), which assumes that people are inherently self-driven because they succeed in obtaining personal satisfaction and self-motivation, but often become alienated due to acquired factors and lose the ability to learn independently. Lin (2018) collated Pintrich's (2000) viewpoints and proposed that autonomous learning is an active and constructive process. In SLR, students will first determine their own learning goals and subsequently monitor, adjust, and control them, which will then motivate them to continue learning. Motivation, cognition, and goal achievement will lead to continuous improvement. If teachers can provide students with the opportunity to control challenges and provide self-assessment, support, and resources by using non-threatening assessment and mastery-oriented teaching strategies, it will help them to learn independently (Perry et al., 2002). Meanwhile, co-regulated learning (CoRL) and social shared regulated learning (SSRL) also support collaborative learning based on SRL. Järvelä and Hadwin's (2013) model involves SRL, CoRL, and SSRL. SSRL extends SRL to include external sources such as peers and teachers, social influences, and group members, to conduct collaborative learning that requires participants to commit to sharing and interacting with others (Hadwin et al., 2017; Panadero, 2017). 
However, students' autonomous learning in science education requires a long training period before they can apply SRL to learning (Eilam \& Reiter, 2014).

Huang and Lin (2014) studied the knowledge integration behavior of pre-employment STEM teachers and pointed out that effective teaching strategies should be adopted to improve cooperation and support among peers, guide students to selfadjust their learning, and gradually enhance students' abilities and confidence. It is important for students to cultivate autonomous learning. If they are able to learn autonomously, they will be motivated and will continue to learn new knowledge by themselves. Autonomous learning has become an integral subject in school education, for improving the current low learning motivation of students and enabling lifelong learning. Therefore, TALP attempts to cultivate students' abilities and motivations in autonomous learning through technological assistance from teachers via teacher feedback.

\section{Research Methods}

This study examined an elementary school located in an urban area in mid-Taiwan. This school utilizes the Ministry of Education's "technology assist self-regulated learning program" (TASRLP) and started using TALP in 2019. Two teachers participated by using TALP in their curriculum, and three fifth-grade classes (A, B, and C) were selected to analyze how TALP influenced their math performance as measured by teacher-administered math assessments. Class A and C started using TALP from 2020, whereas class B started around 2019. However, class A did not use it as often as classes B and C. There were 24, 23, and 26 students in classes A, B, and C, respectively.

This study used mixed methods to conduct data analysis and interviews. This is a program in the TASRLP and the researcher had gained the necessary ethical training qualifications. All participants' names were anonymized and replaced by different names. They joined this research voluntarily. The observation was also conducted publicly and teachers and students were informed about the observation in advance. As a small-scale case study, it was considered appropriate to use nonparametric statistics to analyze test outcomes. This study used the SPSS 20.0 version, with the nonparametric Kruskal-Wallis Test and nonparametric Median Test. These tests were used to analyze whether the class's test scores had significant differences. Meanwhile, due to the COVID-19 situation, qualitative information was provided through online semi-structured interviews and emails using open-ended questions with teachers. Teachers also shared their observation data. Teachers and the researcher interacted and confirmed data validity. Qualitative data can provide insight into the personal experiences and judgments of the participants, offering relevant empirical data to answer the research questions. The observation method can help gain insights and gather information from the field, in this case, how teachers used TALP in their classrooms. It can provide information beyond quantitative data. I observed both teachers' course teaching approaches, integrating TAPL and faceto-face teaching. By using observation in this case study, teacher-student interaction can be included for further analysis. Interviews also allow researchers to gain 
perceptions from stakeholders, helping them learn more about the reality and various perspectives of this case study. However, due to COVID-19, to avoid potential risk to young students, further observations and interviews were cancelled.

\section{Research Results}

This study compared test scores across classes A, B, and C. The outcomes are displayed in Tables 1, 2, and 3 and Fig. 2. These show the comparative statistical analysis of test results among classes. The descriptive statistics in Table 1 show that the three classes had different average scores: both classes A and B had higher math averages compared to class $\mathrm{C}$. The Kruskal-Wallis Test and the Median Test showed no significant differences. In the case study, the time spent using TALP was still quite short (less than a year), the number of participants was quite small, and tests were designed by different teachers, which are possible reasons for why the Kruskal-Wallis Test in Table 2 and the Median Test in Fig. 3 were not significant.

Observations showed that students were interested in participating in class activities. Even students who were less involved in math class (identified by the teachers) showed interest in group discussions. They seemed to be more motivated to participate in class activities of a different kind from before. The interview also confirmed, as reported by the teachers, that TALP and PE can provide important information and assist their teaching activities. Moreover, students are more motivated. The teachers confirmed that using TALP could assist them in identifying students' learning deficits so that they could provide teaching assistance to help overcome students' learning challenges.

For example, consider class $\mathrm{C}$ (fifth-grade). When taking a practice test in the first semester, the test mainly focused on fourth-grade content. The test outcome was bad. Even after teaching them, children still did not understand... In the second semester, the use of TALP led to establish that some students had problems with third grade content. Therefore, third-grade content should be taught. It is positive to find out early about learning challenges to provide treatment on time. This year, in the academic exam (Nationwide), the average math score of our fifth-grade students is above the whole country. The (TALP) effect is great (Alan).

TALP or PE might be very helpful to students whose learning falls behind that of others. The analysis and identification of students' learning problems can support and influence students' learning.

TALP is very useful for learning assistance (especially for low academic performing students) because teachers can design tests (using TALP) to assign different (learning) tasks and examine students' learning conditions from TALP. By using tokens (TALP) and prizes given from the school, these can encourage (and motivate) students' learning. (Max).

The gap among students' math scores is shortened when using TALP (Alan) 


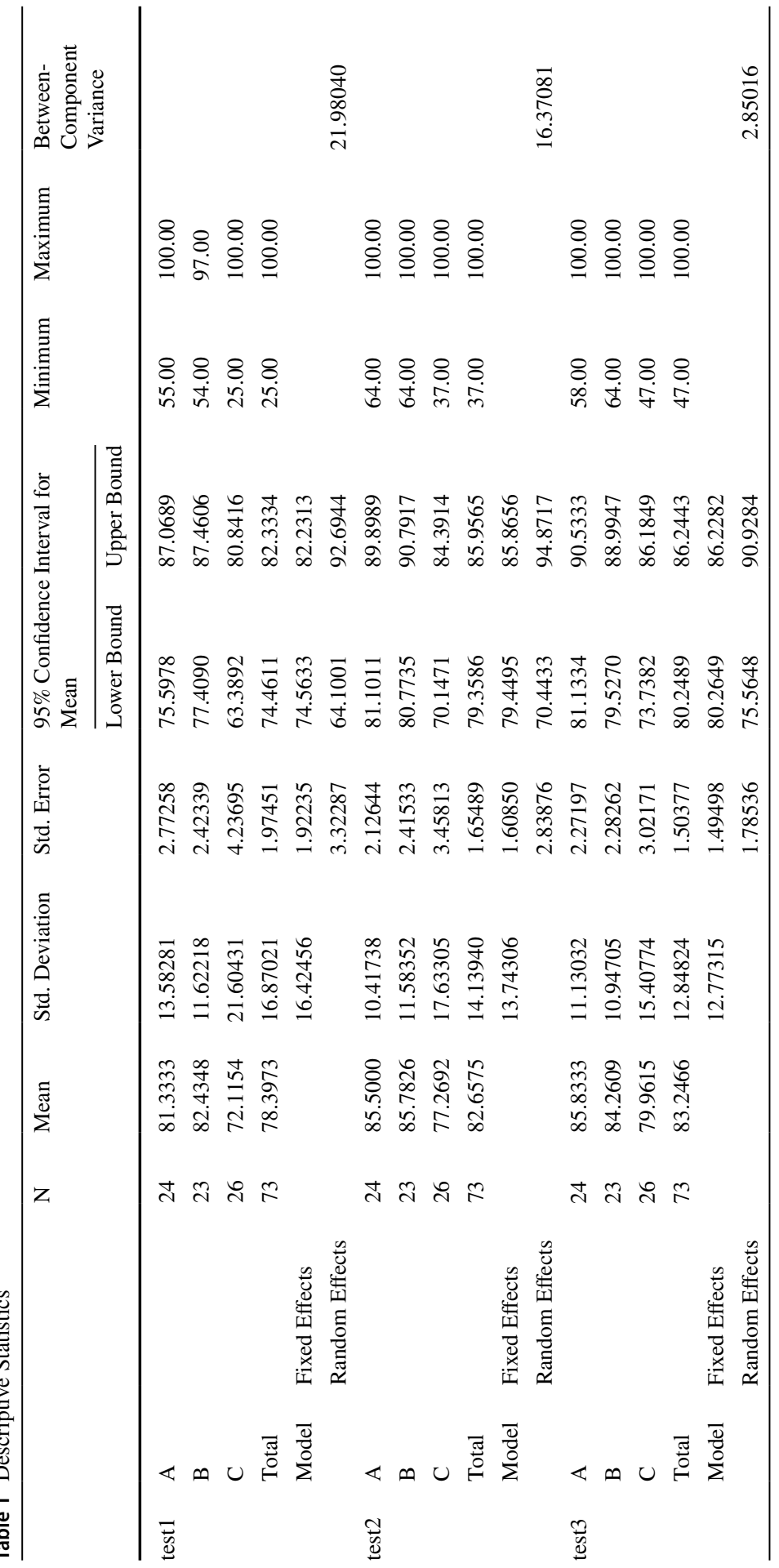




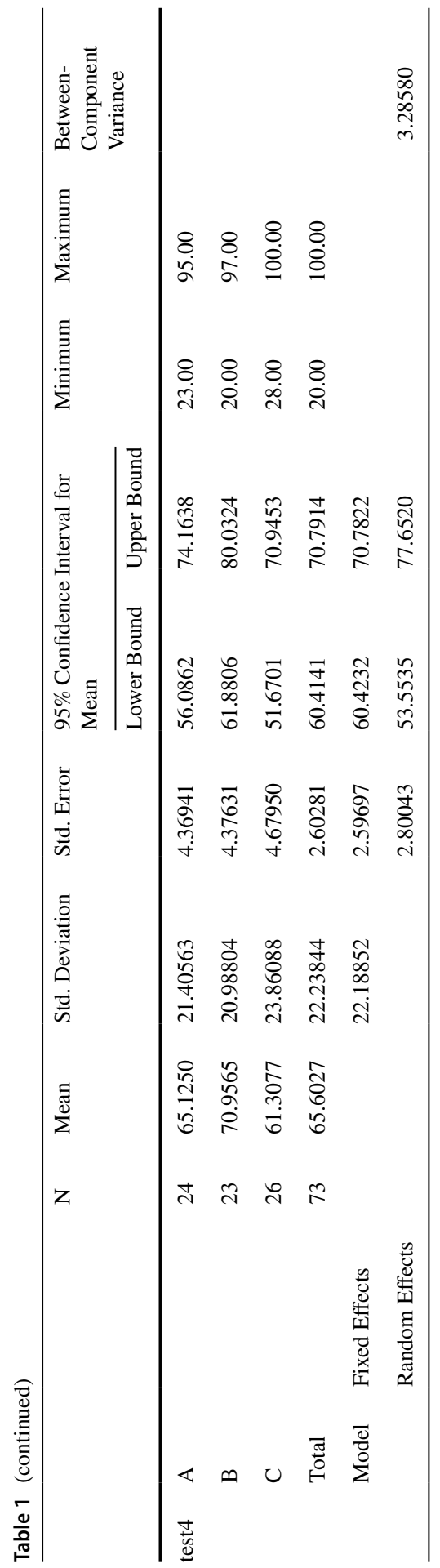


Table 2 Ranks

\begin{tabular}{llll}
\hline Class & & N & Mean Rank \\
\hline test1 & A & 24 & 39.63 \\
& B & 23 & 40.83 \\
& C & 26 & 31.19 \\
test2 & Total & 73 & \\
& A & 24 & 39.67 \\
& B & 23 & 40.98 \\
& C & 26 & 31.02 \\
test3 & Total & 73 & \\
& A & 24 & 40.92 \\
& B & 23 & 37.54 \\
& C & 26 & 32.90 \\
test4 & Total & 73 & \\
& A & 24 & 35.94 \\
& B & 23 & 42.35 \\
& C & 26 & 33.25 \\
& Total & 73 & \\
\hline
\end{tabular}

Table 3 Test Statistics ${ }^{\mathrm{b}}$

\begin{tabular}{lllll}
\hline & test1 & test2 & test3 & test4 \\
\hline Chi-Square & 3.067 & 3.262 & 1.806 & 2.335 \\
df & 2 & 2 & 2 & 2 \\
Asymp. Sig. & .216 & .196 & .405 & .311 \\
\hline
\end{tabular}

a. Kruskal-Wallis Test

b. Grouping Variable: Class

The qualitative data outcomes indicated that TALP can positively increase students' motivation and assist teachers' teaching. PE can be conducted with TALP. Further discussions will be displayed in the next section.

\section{Discussions}

In answering research question 1-“How does TALP assist teachers to conduct PE?"- the qualitative data confirmed that TALP could assist teachers in teaching math. Both teachers from this case study stated that TALP could identify students' learning paths and problems. Based on the analysis, TALP offers learning material and adaptive testing, and teachers can assign students to learn or take tests to personalize learning. This can also be used in future analysis to continuously offer feedback to teachers and students. TALP fulfills PE by offering identification, diagnosis, prediction, and treatment for teaching and learning. The teachers indicated that TALP could not only teach students but could also 
Hypothesis Test Summary

\begin{tabular}{|c|c|c|c|c|}
\hline & Null Hypothesis & Test & Sig. & Decision \\
\hline 1 & $\begin{array}{l}\text { The medians of test } 1 \text { are the same } \\
\text { across categories of Class. }\end{array}$ & $\begin{array}{l}\text { Independent- } \\
\text { Samples } \\
\text { Median Test }\end{array}$ & .136 & $\begin{array}{l}\text { Retain the } \\
\text { null } \\
\text { hypothesis. }\end{array}$ \\
\hline 2 & $\begin{array}{l}\text { The distribution of test } 1 \text { is the same } \\
\text { across categories of Class. }\end{array}$ & $\begin{array}{l}\text { Independent- } \\
\text { Samples } \\
\text { Kruskal-Wallis } \\
\text { Test }\end{array}$ & .216 & $\begin{array}{l}\text { Retain the } \\
\text { null } \\
\text { hypothesis. }\end{array}$ \\
\hline 3 & $\begin{array}{l}\text { The medians of test } 2 \text { are the same } \\
\text { across categories of Class. }\end{array}$ & $\begin{array}{l}\text { Independent- } \\
\text { Samples } \\
\text { Median Test }\end{array}$ & .083 & $\begin{array}{l}\text { Retain the } \\
\text { null } \\
\text { hypothesis. }\end{array}$ \\
\hline 4 & $\begin{array}{l}\text { The distribution of test } 2 \text { is the same } \\
\text { across categories of Class. }\end{array}$ & $\begin{array}{l}\text { Independent- } \\
\text { Samples } \\
\text { Kruskal-Wallis } \\
\text { Test }\end{array}$ & .196 & $\begin{array}{l}\text { Retain the } \\
\text { null } \\
\text { hypothesis. }\end{array}$ \\
\hline 5 & $\begin{array}{l}\text { The medians of test } 3 \text { are the same } \\
\text { across categories of Class. }\end{array}$ & $\begin{array}{l}\text { Independent- } \\
\text { Samples } \\
\text { Median Test }\end{array}$ & .233 & $\begin{array}{l}\text { Retain the } \\
\text { null } \\
\text { hypothesis. }\end{array}$ \\
\hline 6 & $\begin{array}{l}\text { The distribution of test } 3 \text { is the same } \\
\text { across categories of Class. }\end{array}$ & $\begin{array}{l}\text { Independent- } \\
\text { Samples } \\
\text { Kruskal-Wallis } \\
\text { Test }\end{array}$ & .405 & $\begin{array}{l}\text { Retain the } \\
\text { null } \\
\text { hypothesis. }\end{array}$ \\
\hline 7 & $\begin{array}{l}\text { The medians of test } 4 \text { are the same } \\
\text { across categories of Class. }\end{array}$ & $\begin{array}{l}\text { Independent- } \\
\text { Samples } \\
\text { Median Test }\end{array}$ & .293 & $\begin{array}{l}\text { Retain the } \\
\text { null } \\
\text { hypothesis. }\end{array}$ \\
\hline 8 & $\begin{array}{l}\text { The distribution of test } 4 \text { is the same } \\
\text { across categories of Class. }\end{array}$ & $\begin{array}{l}\text { Independent- } \\
\text { Samples } \\
\text { Kruskal-Wallis } \\
\text { Test }\end{array}$ & .311 & $\begin{array}{l}\text { Retain the } \\
\text { null } \\
\text { hypothesis. }\end{array}$ \\
\hline
\end{tabular}

Asymptotic significances are displayed. The significance level is .05 .

Fig. 3 Hypothesis Test Summary

increase their motivation. Students are interested in learning math using digital technology; therefore, it is important to motivate students and help them via STEM education (van den Hurk et al., 2019).

This case study indicates that TALP assisted teachers to conduct PE. The function of prediction and diagnosis of TALP offers PE. TALP can help teachers to identify individual student learning conditions in an easier manner. In this case study, fifth-grade students may have misconceptions or learning gaps from the third grade. TALP showed students' learning problems and teachers could further assist students' learning to overcome the learning gaps. AIED can be used to conduct PE. 
Educational technologies should include those facilitating more adaptive learning systems and PE. This case study confirmed that adaptive learning and PE may enhance teaching and learning, similar to a previous study conducted by $\mathrm{Lu}$ et al. (2018). This case study also showed that AIED and PE can provide important information for teachers, who can adjust their teaching based on PE feedback. PE can identify individual students' learning difficulties, so that teachers can provide personal assistance to different students. AIED can use PE to assist teachers to conduct more personalized teaching based on students' needs. Teachers confirmed that TALP acted as AIED and provided PE that highly assisted their teaching.

In answering research question 2- "How does TALP influence students' learning outcomes in math?"- the qualitative data confirmed that TALP exerted a positive influence. This case study shows that although TALP provides AIED and PE for learning in Taiwan, more follow-up research and curriculum designs are needed to gain the most benefit from TALP. There is controversy over the influence of educational technology. Some studies argue that computer or digital technologies may positively assist math learning (de Witte et al., 2015; Haelermans \& Ghysels, 2017; Machin et al., 2007; Pilli \& Aksu, 2013), while others showed digital technologies had no or negative influence on learning (Campuzano et al., 2009; Leuven et al., 2007). This case study showed the potential benefit of using TALP and PE to enhance the teaching and learning experience.

If more time was invested using TALP and more students had been included, the difference resulting from its application may have been wider. Meanwhile, each test was designed by a different teacher as a particular learning assessment, so different tests may have different difficulty levels and cover different material. The variance among tests and classes can also influence statistical analysis outcomes, especially since these were not standardized tests but midterm and final exams designed by different teachers. Therefore, qualitative methods of data collection can assist our understanding of whether TALP can influence students' math learning outcomes.

TALP showed that PE can help teachers and students to improve their learning and identify their learning problems at an early stage. Moreover, teachers' positive attitude also contributes to the success of use of digital tools (de Witte et al., 2015). Max and Alan both held positive attitudes toward teaching with educational technology in the interview. From the open-ended question data, the two teachers responded that when they used TALP in their teaching, the students improved. Some at-risk students may also have been more motivated and started to improve their learning outcomes. Max indicated that by using TALP, students could take pre-class tests to identify their learning problems. Further, Max could use the analysis outcomes and explain the misconceived ideas in class. Max used TALP and other digital learning resources in his courses, and he also assigned additional materials through TALP and used TALP to monitor students' learning progress. Alan also suggested that TALP could improve students' learning outcomes. Alan claimed that many students in class $\mathrm{C}$ had family issues (including at-risk students) and were accustomed to lower academic performance. Alan stated that using TALP motivated students to improve their learning outcomes.

From observation, students in both class B and C demonstrated interest in learning and participating in the class activities. Both classes used group cooperative 
learning strategies to group students together and guide them to use TALP by discussing answers to questions. They also shared their answers in front of the class. Although class $\mathrm{C}$ had more students who had lower academic performance levels, using TALP, students in class $\mathrm{C}$ remained motivated throughout the course. In Class $\mathrm{C}$, notably, Alan conducted more lectures compared to using group strategies as the students were less experienced in using TALP and with group activities.

The students can access TALP before the class to conduct SRL. In the class group cooperative learning, students can also conduct CoRL and SSRL such that students can learn with peers. Through class observation, most students were highly motivated in the peer cooperative learning activities. Students could share and discuss to solve task challenges. Alan and Max also confirmed that students increased motivation. However, not all students can achieve the ideal of SRL. Both teachers think that some students are starting to conduct SRL and that more time invested in teaching students the skills can improve their SRL.

Therefore, educational technologies, such as AIED or PE in this case study, may be designed to support SRL. This case study also showed that AIED or PE may support SRL, CoRL, and SSRL. The TASRLP encourages design group learning with digital learning to conduct SRL. From teachers' responses, they confirmed that the students had higher motivation and became SRL learners. Students engaged in productive and interactive ways, which can lead to effective collaboration; thus, computer-supported collaborative learning needs to be developed (Dillenbourg et al., 2009). From in-class observation, students in group activities using TALP started to conduct CoRL and SSRL via group discussions, class presentations, and peer interactions. This observation showed a similar conclusion: students may utilize technology to self-regulate their learning (Romero et al., 2019). However, more inquiry is also needed to further confirm the relationship among SRL, CoRL, SSRL, and using educational technologies.

In response to research question 3-"Based on this case study, what can be improved to support PE?"-qualitative data and literature may provide some insights. Additionally, teacher education programs can help to equip teachers with the knowledge and skills to use PE to help their students. Both Max and Alan had participated in some professional workshops about SRL and integrating digital technology in teaching. Professional development or on-job education should offer teachers opportunities to explore how to integrate STEM in their curriculum and emphasize the increase of content knowledge and experience (Margot \& Kettler, 2019). This can impact both the teaching and the students' abilities to learn directly (Nadelson et al., 2013; van Haneghan et al., 2015). Therefore, more professional development programs should be provided to assist teachers in using PE in their classrooms.

The study showed that prediction systems with digital tools can help students to improve their learning performance, especially for low achieving students (Bernacki et al., 2020). This case study confirms such research outcomes within a Taiwan elementary school context. Moreover, this case study can respond to the challenges related to innovation in AIED and pedagogy of digital learning (Barnes et al., 2017), suggesting that TALP can use AI systems to conduct PE and integrate it into daily teaching as a way of digital pedagogy. Max and Alan used TALP in their math 
teaching and analyzed their students' learning situations. Analyzing and predicting students' learning challenges in TALP show not only PE but also AIED, which supports knowledge learning.

This case study revealed that students' grades may improve and their motivation may increase. However, there are some limitations and challenges ahead. First, this was the first year of the TASRLP, so teachers and students lacked experience. This case study also indicated that teachers may need to teach students skills to conduct SRL. Teachers may also need more professional training. Second, this is a smallsample case study limiting its generalization. The MET provides professional workshops to assist teachers to use digital platforms in their teaching. The long-term influences can be further studied and larger-scale research mounted, including initiatives based on learning analytics using national curriculum data. Policymakers can consider the role of the government to support digital learning and AIED compared with private firms offering the similar AIED. The MET has dedicated another two years to extending the TASRLP and conducted an official SRL survey. MET will also provide about $\$ 700$ million (USD) dollars to support digital learning from 2022 to 2025. The continuous study of AIED and PE along with the supporting digital learning policy is also important for future researches. Lastly, a more in-depth study of AIED and PE influences on students' SRL would be valuable future research endeavors.

\section{Conclusions}

This study used TALP in an elementary school in a case study on practical PE. Although the quantitative data showed no significant differences among the classes using TALP for several reasons, such as time limitations, non-standardized tests, and small sample size, they did show that PE can assist in teaching and learning. The teachers observed and responded that students who used TALP were more motivated and improved their learning outcomes. Teachers could also identify students' learning gaps and problems in the early stages by using TALP with its PE system, and they could use TALP and other materials to assist students in their learning. This case study confirms previous studies (Berendt et al., 2020; Martin et al., 2020; van Alten et al., 2020) that technology can enhance student learning. Moreover, this case study also supported that TALP and PE can assist in teaching and learning math and at some points, even support students' SRL.

The case study also indicated the positive potential effect of using PE in classrooms. The teachers responded that TALP could help them enhance their teaching effectiveness and learning experience. Extending or innovating the use of digital technology to conduct PE should be further explored. Teachers should be provided with professional development so that they are capable of using digital technology or PE to improve their teaching in STEM. A longitudinal study could be applied to track the influence of TALP or other PE applications, and interviewing students and observing classroom teaching is also suggested for future studies. Some standardized tests can be used for future quasi-experimental studies. 


\section{Declarations}

Conflict of Interest I would like to mention that a potential conflict of interest is likely because I am the regional co-director of Taiwan's "technology assisted self-regulated learning (SRL) project." However, I have tried to adhere to an objective and scientific stance in this study, as best as possible.

\section{References}

Asghar, A., Ellington, R., Rice, E., Johnson, F., \& Prime, G. M. (2012). Supporting STEM education in secondary science contexts. Interdisciplinary Journal of Problem-Based Learning, 6(2), 85-125.

Bagiati, A., \& Evangelou, D. (2015). Engineering curriculum in the preschool classroom: The teacher's experience. European Early Childhood Education Research Journal, 23(1), 112-128.

Bandura, A. (1986). Social foundations of thought and action: A social cognitive theory. Prentice Hall.

Barnes, T., Boyer, K., Hsiao, S. I. H., Le, N. T., \& Sosnovsky, S. (2017). Preface for the special issue on AI-supported education in computer science. International Journal of Artificial Intelligence in Education, 27(1), 1-4. https://doi.org/10.1007/s40593-016-0123-y

Behnamnia, N., Kamsin, A., Ismail, M. A. B., \& Hayati, A. (2020). The effective components of creativity in digital game-based learning among young children: A case study. Children and Youth Services Review, 116, 1-13. https://doi.org/10.1016/j.childyouth.2020.105227

Beilock, S. L., \& Willingham, D. T. (2014). Math anxiety: Can teachers help students reduce it? American Educator, 38(2), 28-32.

Berendt, B., Littlejohn, A., \& Blakemore, M. (2020). AI in education: Learner choice and fundamental rights. Learning, Media and Technology, 45(3), 312-324. https://doi.org/10.1080/17439884.2020. 1786399

Bernacki, M. L., Chavez, M. M., \& Uesbeck, P. M. (2020). Predicting achievement and providing support before STEM majors begin to fail. Computers and Education, 158. https://doi.org/10.1016/j.compe du.2020.103999

Box, C., Skoog, G., \& Dabbs, J. M. (2015). A case study of teacher personal practice assessment theories and complexities of implementing formative assessment. American Educational Research Journal, 52(5), 956-983. https://doi.org/10.3102/0002831215587754

Braun, M., Hummel, P., Beck, S., \& Dabrock, P. (2020). Primer on an ethics of AI-based decision support systems in the clinic. Journal of Medical Ethics, 1-8.

Bruce-Davis, M. N., Gubbins, E. J., Gilson, C. M., Villanueva, M., Foreman, J. L., \& Rubenstein, L. D. (2014). STEM high school administrators', teachers', and students' perceptions of curricular and instructional strategies and practices. Journal of Advanced Academics, 25(3), 272-306.

Campuzano, L., Dynarski, M., Agodini, R., \& Rall, K. (2009). Effectiveness of reading and mathematics software products: Findings from two student cohorts. Retrieved from: https://files.eric.ed.gov/fullt ext/ED504657.pdf. Washington, DC: Institute of Education Sciences, National Center for Education Evaluation and Regional Assistance.

Castells, M. (2011). The rise of the network society (second edn.). West Sussex: Wiley.

Chang, E. (2019). Beyond workforce preparation: Contested visions of 'Twenty-First Century' Education Reform. Discourse: Studies in the Cultural Politics of Education, 40(1), 29-45.

Dare, E. A., Ellis, J. A., \& Roehrig, G. H. (2014). Driven by beliefs: Understanding challenges physical science teachers face when integrating engineering and physics. Journal of Pre-College Engineering Education Research, 4(2), 47-61.

Das, A. K. (2018). Best adaptive learning platforms for professional development. Retrieved from: https:// indvstrvs.com/best-adaptive-learning-platforms-2018/.

de Witte, K., Haelermans, C., \& Rogge, N. (2015). The effectiveness of a computer-assisted math learning program. Journal of Computer Assisted Learning, 31(4), 314-329. https://doi.org/10.1111/jcal. 12090

Deci, E. L., \& Ryan, R. M. (2008). Self-determination theory: A macrotheory of human motivation, development, and health. Canadian Psychology, 49(3), 182-185. https://doi.org/10.1037/a0012801

Dillenbourg, P., Jarvela, S., \& Fisher, F. (2009). The evolution of research on computer-supported collaborative learning: From design to orchestration. In N. Balacheff, S. Ludvigsen, T. De Jong, A. 
Lazonder, \& S. Barnes (Eds.), Technology-enhanced learning: Principles and products (pp. 3-19). Springer.

Efklides, A. (2011). Interactions of metacognition with motivation and affect in self-regulated learning: The MASRL model. Educational Psychologist, 46(1), 6-25.

Eilam, B., \& Reiter, S. (2014). Long-Term self-regulation of biology learning using standard junior high school science curriculum. Science Education, 98(4), 705-737.

El-Deghaidy, H., Mansour, N., Alzaghibi, M., \& Alhammad, K. (2017). Context of STEM integration in schools: Views from in-service science teachers. Eurasia Journal of Mathematics, Science and Technology Education, 13(6), 2459-2484.

Finlayson, M. (2014). Addressing math anxiety in the classroom. Improving Schools, 17(1), 99-115.

Fischer, C., Pardos, Z. A., Baker, R. S., Williams, J. J., Smyth, P., Yu, R., et al. (2020). Mining big data in education: Affordances and challenges. Review of Research in Education, 44(1), 130-160.

Fishman, B. J., \& Davis, E. A. (2006). Teacher learning research and the learning sciences. In R. K. Sawyer (Ed.), The Cambridge handbook of the learning sciences (pp. 535-550). Cambridge University Press.

Gafoor, K. A., \& Kurukkan, A. (2015). Why high school students feel mathematics difficult? An exploration of affective beliefs. Retrieved from: https://files.eric.ed.gov/fulltext/ED560266.pdf.

Gaspard, H., Dicke, A. L., Flunger, B., Brisson, B. M., Häfner, I., Nagengast, B., \& Trautwein, U. (2015). Fostering adolescents' value beliefs for mathematics with a relevance intervention in the classroom. Developmental Psychology, 51(9), 1226-1240.

Goodpaster, K. P. S., Adedokun, O. A., \& Weaver, G. C. (2012). Teachers' perceptions of rural STEM teaching: Implications for rural teacher retention. Rural Educator, 33(3), 9-22.

Hadwin, A. F., Järvelä, S., \& Miller, M. (2017). Self-regulation, co-regulation and shared regulation in collaborative learning environments. In D. H. Schunk \& J. A. Greene (Eds.), Handbook of selfregulation of learning and performance (second edn.), pp. 83-106. Routledge.

Haelermans, C., \& Ghysels, J. (2017). The effect of individualized digital practice at home on math skills-Evidence from a two-stage experiment on whether and why it works. Computers and Education, 113, 119-134.

Herro, D., \& Quigley, C. (2017). Exploring teachers' perceptions of STEAM teaching through professional development: Implications for teacher educators. Professional Development in Education, 43(3), 416-438.

Hsu, M. C., Purzer, S., \& Cardella, M. E. (2011). Elementary teachers' views about teaching design, engineering, and technology. Journal of Pre-College Engineering Education Research, 1(2), 31-39.

Huang, T.-J., \& Lin, K.-Y. (2014). A study on pre-service teachers' knowledge integration behaviors in STEM-based hands-on learning activity. Technology and Human Education Quarterly, 1(1), 18-39.

Hussein, M. H., Ow, S. H., Elaish, M. M., \& Jensen, E. O. (2021). Digital game-based learning in K-12 mathematics education: A systematic literature review. Education and Information Technologies. https://doi.org/10.1007/s10639-021-10721-x.

Ideland, M. (2021). Google and the end of the teacher? How a figuration of the teacher is produced through an ed-tech discourse. Learning, Media and Technology, 46(1), 33-46. https://doi.org/10. 1080/17439884.2020.1809452

Jarke, J., \& Breiter, A. (2019). Editorial: The datafication of education. Learning, Media and Technology, 44(1), 1-6. https://doi.org/10.1080/17439884.2019.1573833

Järvelä, S., \& Hadwin, A. F. (2013). New frontiers: Regulating learning in CSCL. Educational Psychologist, 48(1), 25-39. https://doi.org/10.1080/00461520.2012.748006

Kara, Y., \& Yeşilyurt, S. (2008). Comparing the impacts of tutorial and edutainment software programs on students' achievements, misconceptions, and attitudes towards biology. Journal of Science Education and Technology, 17(1), 32-41.

Kerssens, N., \& Dijck, J. (2021). The platformization of primary education in the Netherlands. Learning, Media and Technology, 46(3), 250-263. https://doi.org/10.1080/17439884.2021.1876725

Kundu, A., Bej, T., \& Rice, M. (2021). Time to engage: Implementing math and literacy blended learning routines in an Indian elementary classroom. Education and Information Technologies, 26(1), 1201-1220. https://doi.org/10.1007/s10639-020-10306-0

Lesseig, K., Nelson, T. H., Slavit, D., \& Seidel, R. A. (2016). Supporting middle school teachers' implementation of STEM design challenges. School Science and Mathematics, 116(4), 177-188.

Leuven, E., Lindahl, M., Oosterbeek, H., \& Webbink, D. (2007). The effect of extra funding for disadvantaged pupils on achievement. Review of Economics and Statistics, 89(4), 721-736. 
Lin, T. H. (2018). Five major development trends of selfregulated learning. Journal of Education and Research, 295, 126-145.

Lu, O., Huang, A., Huang, J., Lin, A., Ogata, H., \& Yang, S. J. H. (2018). Applying learning analytics for the early prediction of students' academic performance in blended learning. Journal of Educational Technology and Society, 21(2), 220-232.

Machin, S., McNally, S., \& Silva, O. (2007). New technology in schools: Is there a payoff? The Economic Journal, 117(522), 1145-1167.

Margot, K. C., \& Kettler, T. (2019). Teachers' perception of STEM integration and education: A systematic literature review. International Journal of STEM Education, 6(1), 2.

Martin, F., Sun, T., \& Westine, C. D. (2020). A systematic review of research on online teaching and learning from 2009 to 2018. Computers and Education, 159, 104009. https://doi.org/10.1016/j. compedu.2020.104009

McMullin, K., \& Reeve, E. (2014). Identifying perceptions that contribute to the development of successful project lead the way pre-engineering programs in Utah. Journal of Technology Education, 26(1), 22-46.

Moore, T. J., Stohlmann, M. S., Wang, H. H., Tank, K. M., Glancy, A., \& Roehrig, G. H. (2014). Implementation and integration of engineering in K-12 STEM education. In J. Strobel, S. Purzer, \& M. Cardella (Eds.), Engineering in precollege settings: Research into practice (pp. 35-60). Sense Publishers.

Nadelson, L. S., \& Seifert, A. (2013). Perceptions, engagement, and practices of teachers seeking professional development in place-based integrated STEM. Teacher Education and Practice, 26(2), 242-265.

Nadelson, L. S., Callahan, J., Pyke, P., Hay, A., Dance, M., \& Pfiester, J. (2013). Teacher STEM perception and preparation: Inquiry-based STEM professional development for elementary teachers. Journal of Educational Research, 106(2), 157-168.

Panadero, E. (2017). A review of self-regulated learning: Six models and four directions for research. Frontiers in Psychology, 8(422), 422. https://doi.org/10.3389/fpsyg.2017.00422

Park, H., Byun, S. Y., Sim, J., Han, H. S., \& Baek, Y. S. (2016). Teachers' perceptions and practices of STEAM education in South Korea. Eurasia Journal of Mathematics, Science and Technology Education, 12(7), 1739-1753.

Park, M., Dimitrov, D. M., Patterson, L. G., \& Park, D. (2017). Early childhood teachers' beliefs about readiness for teaching science, technology, engineering, and mathematics. Journal of Early Childhood Research, 15(3), 275-291.

Perry, N. E. (2002). Introduction: Using qualitative methods to enrich understandings of self -regulated learning. Educational Psychologist, 37(1), 1-3.

Perry, N. E., VandeKamp, K. O., Mercer, L. K., \& Nordby, C. J. (2002). Investigating teacher-student interactions that foster self-regulated learning. Educational Psychologist, 37(1), 5-15.

Pilli, O., \& Aksu, M. (2013). The effects of computer-assisted instruction on the achievement, attitudes and retention of fourth grade mathematics students in North Cyprus. Computers and Education, 62, $62-71$.

Pintrich, P. R. (2000). The role of goal orientation in self-regulated learning. Retrieved from: http://cache scan.bcub.ro/e-book/E1/580704/451-529.pdf.

Prokop, P., Lešková, A., Kubiatko, M., \& Diran, C. (2007). Slovakian students' knowledge of and attitudes toward biotechnology. International Journal of Science Education, 29(7), 895-907.

Ramirez, G., Hooper, S. Y., Kersting, N. B., Ferguson, R., \& Yeager, D. (2018). Teacher math anxiety relates to adolescent students' math achievement. AERA Open, 4(1). https://doi.org/10.1177/23328 58418756052

Romero, L., Saucedo, C., Caliusco, M. L., \& Gutiérrez, M. (2019). Supporting self-regulated learning and personalization using ePortfolios: A semantic approach based on learning paths. International Journal of Educational Technology in Higher Education, 16(1). doi:https://doi.org/10.1186/ s41239-019-0146-1.

Russell, S., \& Norvig, P. (2016). Artificial intelligence: A modern approach. Retrieved from: http://aima. cs.berkeley.edu/

Self, J. (2016). The birth of IJAIED. International Journal of Artificial Intelligence in Education, 26(1), 4-12.

Selwyn, N. (2020). Digital education in the aftermath of COVID-19: Critical concerns \& hopes. Retrieved from: http://der.monash.edu/wp-content/uploads/2020/06/TECHLASH-01-COVID-educa tion.pdf 
Shafique, M., \& Irwin-Robinson, H. (2015). A study on the effectiveness of flipped teaching in college math classroom. International Journal of Education and Information Technology, 1(2), 29-33.

Sherwin, T. (2020). Math anxiety and growth mindset: Building teacher efficacy (Unpublished Master's thesis). Canada: Concordia University of Edmonton.

UNESCO (2020). Education in a post-Covid world. Nine ideas for public action. Retrieved from: https:// en.unesco.org/news/education-post-covid-world-nine-ideas-public-action

van Alten, D. C. D., Phielix, C., Janssen, J., \& Kester, L. (2020). Self-regulated learning support in flipped learning videos enhances learning outcomes. Computers and Education, 158. https://doi.org/ 10.1016/j.compedu.2020.104000.

van den Hurk, A., Meelissen, M., \& Van Langen, A. (2019). Interventions in education to prevent STEM pipeline leakage. International Journal of Science Education, 41(2), 150-164.

van Haneghan, J. P., Pruet, S. A., Neal-Waltman, R., \& Harlan, J. M. (2015). Teacher beliefs about motivating and teaching students to carry out engineering design challenges: Some initial data. Journal of Pre-College Engineering Education Research, 5(2), 1-9.

Wang, H. H., Moore, T. J., Roehrig, G. H., \& Park, M. S. (2011). STEM integration: Teacher perceptions and practice. Journal of Pre-College Engineering Education Research, 1(2), 1-13.

Wiliam, D., \& Leahy, S. (2006, April). A theoretical foundation for formative assessment. Paper presented at the American Educational Research Association annual meeting, San Francisco, CA.

Williamson, B., \& Hogan, A. (2020). Commercialisation and Privatisation in/of Education in the Context of Covid-19. Retrieved from: https://issuu.com/educationinternational/docs/2020_eiresearch_gr_ commercialisation_privatisation.

Williamson, B., Bergviken Rensfeldt, A., Player-Koro, C., \& Selwyn, N. (2019). Education recoded: Policy mobilities in the international "learning to code" agenda. Journal of Education Policy, 34(5), $705-725$.

Williamson, B., Eynon, R., \& Potter, J. (2020). Pandemic politics, pedagogies and practices: Digital technologies and distance education during the coronavirus emergency. Learning, Media and Technology, 45(2), 107-114. https://doi.org/10.1080/17439884.2020.1761641

Yang, S. J. H. (2019). Precision education: New challenges for AI in education. Paper presented at the 27th International Conference on Computers in Education, Howard Beach Resort, Kenting, Taiwan.

Young, A. J. (1997). I think, therefore I'm motivated: The relations among cognitive strategy use, motivational orientation and classroom perceptions over time. Learning and Individual Differences, 9(3), 249-283.

Zimmerman, B. J. (1988). Developing self-fulfilling cycles of academic regulation: An analysis of exemplary instructional models. Retrieved from: http://psycnet.apa.org/record/1998-07519-001.

Zimmerman, B. J. (1990). Self-regulated learning and academic achievement: An overview. Educational Psychologist, 25(1), 3-17.

Zimmerman, B. J., \& Kitsantas, A. (1997). Developmental phases in self-regulation: Shifting from process goals to outcome goals. Journal of Educational Psychology, 89(1), 29-36.

Zimmerman, J. (2020). "Coronavirus and the great online-learning experiment." Chronicle of Higher Education, Accessed March 10. Retrieved from: https://www.chronicle.com/article/CoronavirustheGreat $/ 248216$

Publisher's note Springer Nature remains neutral with regard to jurisdictional claims in published maps and institutional affiliations. 